\title{
Real-Time Virtual Sonography in Gynecology \& Obstetrics: Literature's Analysis and Case Series
}

\author{
F. Torcia* MD, F. Bellati* MD/PhD, M. P. De Marco* MD, F. Costanzi* MD, F. Manurita* MD, E. Taloni* MD, D. Caserta* \\ $\mathrm{MD} / \mathrm{PhD}$
}

*Department of Medical and Surgical Sciences and Translational Medicine, Sant'Andrea Hospital, School of Medicine and Psychology, University of Rome "Sapienza", Italy

Received: 輼: October 03, 2018; Published: 制: October 11, 2018

*Corresponding author: Donatella Caserta, Department of Medical and Surgical Sciences and Translational Medicine, Sant' Andrea Hospital, School of Medicine and Psychology, University of Rome "Sapienza", Italy

\begin{abstract}
Fusion Imaging is a latest generation diagnostic technique, designed to combine ultrasonography with a second-tier technique such as magnetic resonance imaging and computer tomography. It has been mainly used until now in urology and hepatology. Concerning gynecology and obstetrics, the studies mostly focus on the diagnosis of prenatal disease, benign pathology and cervical cancer. We provided a systematic review of the literature with the latest publications regarding the role of Fusion technology in gynecological and obstetrics fields and we also described a case series of six emblematic patients enrolled from Gynecology Department of Sant 'Andrea Hospital, "la Sapienza", Rome, evaluated with Esaote Virtual Navigator equipment. We consider that Fusion Imaging could add values at the diagnosis of various gynecological and obstetrics conditions, but further studies are needed to better define and improve the role of this fascinating diagnostic tool.
\end{abstract}

Abbreviations: RVS: Real-Time Virtual Sonography; MRI: Magnetic Resonance Imaging; CT: Computed Tomography

\section{Introduction}

The technological evolution reached led to a more patient tailored diagnostic approach. Actually, the tendency is to use integrated and synchronized analyzes in order to connect data from multiple diagnostic sources, modifying the clinical and diagnostic approach. The traditional radiology practice evaluates imaging using multiple techniques through visualization of images, multimedia or paper format, in a process called "co-registration". This process consists of finding a suitable spatial matching between the results shown in images detected with different modes. The reader's experience and interpretive capacity are extremely relevant. Fusion Imaging or Real-Time Virtual Sonography (RVS) is a revolutionary radiological technique that allows the sequential overlap of a series of radiological images obtained from the study of an organ or body region with different detection systems. It allows the use ultrasound imaging with all its diagnostic features (grayscale, real-time, Doppler, elastosonography) with the fusion of images obtained from Magnetic Resonance Imaging (MRI) or Computed Tomography (CT).

This process translates into a virtual navigation that exploits the potential benefits of different imaging techniques providing a specific, real-time and low-cost exam. The well-known advantages of ultrasonography are added to the standardized second level techniques (MRI, CT, PET) such as high resolution, contrast power, non-operator dependence, extensive field view. Fields of application may range from the use in the clinical diagnostic practice, such as pre-surgical management of suspected lesions, to intervention procedures and finally for research and training. Being an innovative method, the literature regarding Fusion Imaging is still poor. Major areas of interest of this technique are urology and hepatology. Concerning gynecology and obstetrics, the first researches are focusing on the diagnosis of endometriosis, adenomyosis, cervical cancer and prenatal diseases. The aim of this study is to report a review of the present literature, supplemented with our case series of patients carried out at the Gynecology Department of Sant 'Andrea Hospital, La Sapienza University, in Rome, that stimulates the research to investigate where RVS could be useful as a diagnostic, prognostic and therapeutic tool. We will report only the cases that have been more explicit in the method.

\section{Fusion Tool}

Real-Time Virtual Sonography is performed using pictures obtained from preoperative MRI or CT scan with the aim to study pathologies in an integrated way. This new technique allows to synchronize with a single device, through the same software, two or more imaging methods, overlapping and activating them with the simple classic movement of the ultrasound transducer. The software includes a magnetic field transmitter which sends signals to a position sensor placed on a suitable support that wraps the selected probe. The magnetic field transmitter should be placed close to the area to be evaluated. During scanning, the magnetic detection system determines the position and movement of the 
sensor attached to the transducer within the defined volume. The probe must be placed within a range of 20 to $70 \mathrm{~cm}$ from the magnetic field transmitter.

To simultaneously analyze images from two different techniques, the placement of a so called "target" in common with the two methods is needed. The exam consists of three phases: registration, tuning and navigation. During recording, the appropriate probe is chosen, and external markers are positioned to perform biopsies. Anybody district can be studied with Fusion thanks to the use of a wide range of transducers:

a) convex probes (2D and 3D) in abdominal and obstetrics applications

b) linear probes (2D and 3D) are useful for studying superficial tissues, such as the thyroid, the breast, the muscles, the tendons, the breast and the axillary cavity

c) end cavitary probes for urological and gynecological investigations and particular obstetric conditions

d) linear intraoperative probes for surgery

e) dedicated interventional probes for abdominal biopsies.

To achieve the second phase, a manual target is set instead. Tuning consists in coinciding with the ultrasound image with that of the magnetic resonance or CT thanks to the "overlap" function of the software. Finally, there is the navigation phase of the image generated by the simultaneous visualization of the sonographic volumes with those of the magnetic resonance or computed tomography. The navigation presents numerous applications, in fact, it can also be used for interventional and ablation procedures because it allows delineation of lesion's margins and the computerized calculation of its volumes. It is necessary to align the two images by "frizzing" the MRI in the chosen plane, scanning the patient in order to find the same investigation plan and select an adaptation key to start visualizing the two methods simultaneously. It is also possible to reverse the operation by first frying the ultrasound image and then finding the corresponding one in RM. To facilitate the procedure, it is possible to select different RM sequences; the sonographic system independently provides to convert each sequence into a volume to obtain a final one, consisting of the union of each scan.

\section{Material \& Methods}

\section{Systematic Literature Review}

We conducted a computerized Medline, PubMed, Embase, and the Cochrane Collaboration Registry of Controlled Trials search until March 30th 2018, using the following key words: "Fusion Imaging", "Real time virtual sonography" "MRI/US",'CT/US", "gynecological imaging", "obstetrics imaging", "sonography", "ultrasound", "MRI", "CT", “CEUS", "MRI prenatal diagnosis", "prenatal diagnosis", "prenatal ultrasound", "endometriosis", "adenomyosis" , "ovarian disease", "female cancer", "endometrial cancer", "ovarian cancer", "cervical cancer", "target biopsy". Studies bibliographies were also checked and analyzed. Pertinent-full texts were selected and reviewed, and its reference lists were manually searched in order to identify other useful articles. The retrieval was extended to all the possible study type, only two limitations have been applied: the study has to be in English language and conducted in humans. 12 studies have been evaluated for the obstetrician and gynecological pathology but 7 were excluded because they didn't use Fusion Imaging tool, but other examination procedures such as 3D sonography. So, we report 3 gynecological and 2 obstetrics studies that investigate patients with RVS as shown in Tables $1 \& 2$.

Table 1: Obstetrics applications of RVS described in literature.

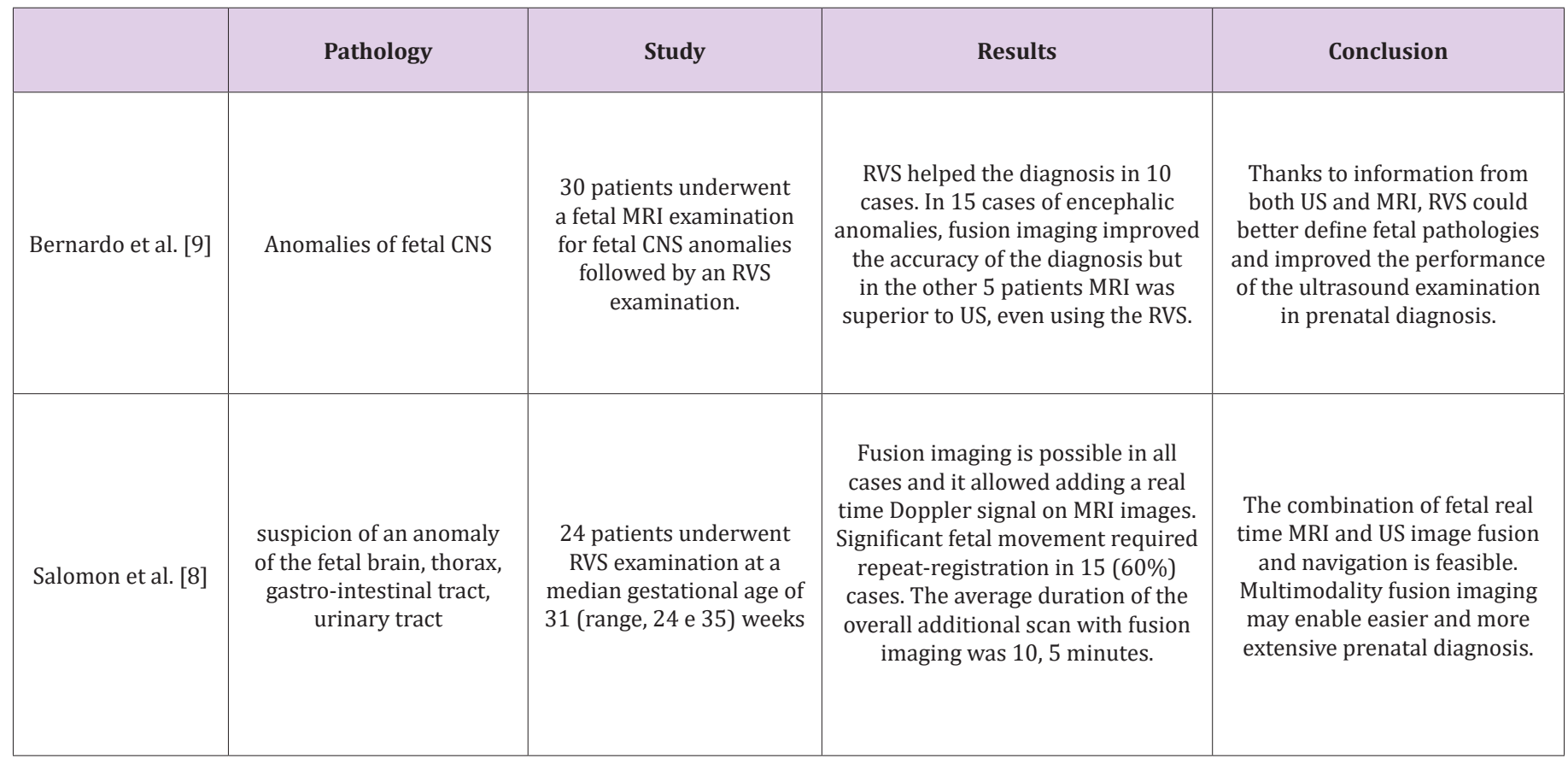


Table 2: Gynecologic applications of RVS described in literature.

\begin{tabular}{|c|c|c|c|c|}
\hline & Pathology & Study & Results & Conclusion \\
\hline Vinci et al. [20] & adenomyosis & $\begin{array}{l}52 \text { women underwent US, MRI } \\
\text { and RVS examination }\end{array}$ & $\begin{array}{l}\text { US compared with MRI misdiagnosed } 3 \\
\text { cases. RVS confirmed all cases }\end{array}$ & $\begin{array}{l}\text { RVS in could improve diagnosis of } \\
\text { adenomyosis and performance of } \\
\text { TVS operator. }\end{array}$ \\
\hline $\begin{array}{l}\text { Millischer et al. } \\
\qquad[18]\end{array}$ & endometriosis & $\begin{array}{l}17 \text { women who had an MRI } \\
\text { examination in a time interval } \\
\text { between the MRI and US of } 171 \\
\text { days, underwent US and RVS } \\
\text { examination }\end{array}$ & $\begin{array}{c}\text { uterosacral ligaments: US } 88 \% \text {, MRI } \\
\text { 100\%, RVS 100\%; posterior vaginal } \\
\text { fornix: US } 82 \% \text {, MRI 100\%, RVS 100\%; } \\
\text { rectum: US 100\%, MRI 82,3, RVS } 100 \% \text {; } \\
\text { ureters: US 0\%, MRI 100\%, RVS 100\%; } \\
\text { bladder: US: } 100 \% \text {, MRI: } 100 \% \text {, RVS: } \\
100 \% \text {. }\end{array}$ & $\begin{array}{l}\text { RVS better identificates lesions } \\
\text { of deep endometriosis and could } \\
\text { improve the performance of TVS } \\
\text { operator. }\end{array}$ \\
\hline $\begin{array}{l}\text { Theodore et al. } \\
\qquad[24]\end{array}$ & Cervical cancer & $\begin{array}{l}13 \text { women underwent US, MRI } \\
\text { and RVS examination }\end{array}$ & $\begin{array}{c}\text { Final diagnosis was obtained in all } \\
\text { patients }(100 \%) \text { with fusion imaging } \\
\text { and in } 12(92 \%) \text { with MRI. The } \\
\text { concordance rate between classic } \\
\text { ultrasonography and fusion imaging } \\
\text { was 50\% for parametrium involvement } \\
\text { and } 85 \% \text { between MRI and fusion } \\
\text { imaging. }\end{array}$ & $\begin{array}{l}\text { Fusion imaging could be used } \\
\text { as a complementary technique } \\
\text { for MRI to enhance diagnostic } \\
\text { performance for cervical cancer } \\
\text { lesions, detecting parametrium } \\
\text { infiltration by exploration of } \\
\text { the stromal ring and vascular } \\
\text { bridge, thanks to the use of color } \\
\text { Doppler mode in Fusion Imaging. } \\
\text { RVS imaging could improve MRI } \\
\text { information. }\end{array}$ \\
\hline
\end{tabular}

\section{Case Series}

A total of 20 patients were enrolled between March 2018 and June 2018 at the Gynecology Department of Sant' Andrea Hospital, la Sapienza in Rome.

Study inclusion criteria were:

a) established diagnosis of the following conditions: benign or malignant ovarian mass, neoplasia of endometrium;

b) preoperative MRI and / or CT images;

c) performed surgery

Out of 20 patients, 6 responded to all inclusion criteria established for the study. The remaining 14 patients were excluded from the present study for lack of surgical intervention or imaging information and, consequently, they were less demonstrative of the value of the instrument. The fusion technology was performed with Esaote Virtual Navigator equipment (Figure 1), using pictures obtained from preoperative MRI or CT scan. Results were analyzed using OsiriX, radiological software, to obtain five repeated measures to ensure the goodness of the experimental data. Considering the heterogeneity of clinical cases and the small number of patients, we performed a sample diagnostic accuracy analysis considering its standard deviation.

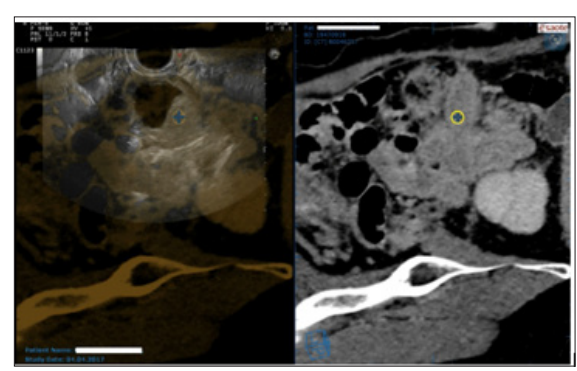

Figure 1: Patient 1, left ovary US/CT overlap images.

\section{Results}

\section{Systematic Literature Review}

Studies on the gynecologic and obstetric application of Fusion Imaging are still poor and mainly focused on prenatal diagnosis, endometriosis, adenomyosis and cervical cancer.

Prenatal Diagnosis: In obstetrics, prenatal diagnosis of the fetus is at the center of pregnancy care and management in all the most developed countries [1]. It is mainly performed through ultrasound, Doppler color [2] and 3D use. This imaging mode is widely available and allows a fast evaluation of the fetus. For certain conditions, other techniques, such as prenatal MRI, may be indicated [3-7]. MRI provides a good visualization of both fetal anatomy and tissue characteristics [7] and it is less hampered by maternal or fetal factors such as fetal position, advanced gestational age, multiple pregnancy and obesity. MRI has limited availability and does not provide complete real-time images, even if dynamic sequences can be obtained. Moreover, it doesn't allow the use of Doppler technology. Following these considerations, an association of MRI with real-time ultrasound images might be interesting for prenatal diagnosis. The study by Salomon L. J. et al. shows that MR-US Fusion Imaging is relevant in prenatal diagnosis as the two modes are efficiently completed for certain indications, but it highlights the limits of this technique.

Salomon has demonstrated that, once the anatomic plans and reference points used for ultrasound recording and previous volumes, acquired through MRI, have been defined, the precision of the image depends on fetal growth and spontaneous fetal movement during the examination which may limit the acquisition of the fused images. The study shows that with a short interval between the two exams the detection could be more accurate, while longer time intervals could lead to a complete change in fetal position with a more complex recording. In addition, fetal growth can permanently influence and compromise proper image recording [8]. Combining 
the two techniques proved to be safe and free of risk for the fetus. A recent prospective study by Bernardo et al. [9] confirmed that it is possible to combine real-time ultrasonography and multiplanar reconstructed Magnetic Resonance images with RVS to evaluate fetal pathologies [9]. Purpose of the study was to submit to the RVS analysis the fetus in which had been found US abnormalities. Different pathologies involving the nervous system have been considered for the RVS investigation, such as ventriculomegaly (hydrocephalus), the suspicion of a cerebral/cerebellar hemorrhage and agenesis of the corpus callosum. 30 women were included in the study, between 18 and 30 weeks pregnant.

The patients in whom the fetal pathological signs were found with the US, were submitted to MRI in a short time interval (from 1 hour up to 1 day), in order to avoid anatomical changes and position of the fetus. Obtained the results from the MRI, the investigation with RVS was carried out. As a target (reference point) for the head of the fetus was chosen the cavum of the septum pellucidum or the eye. The RVS study was conducted via the axial and coronal planes. RVS has shown an 80 to $100 \%$ accuracy of matching between MRI and US analysis. The gap is due to the synchronization of images due to fetal movements. The best resolution of the RVS was the evaluation of isolated ventriculomegaly; in cases of secondary ventriculomegaly associated with intraventricular hemorrhage, MRI showed a higher accuracy. This data may be due to the improved resolution of the various types of tissues by the magnetic resonance. This article also demonstrates the advantage of RVS in enhancing the precise site and the extent of an ischemic hemorrhagic lesion, detected by MRI; in this way, the follow up of these patients can be followed only by US, unique in terms of availability and tolerance by the patient. So RVS could be really helpful in pathologies that would benefit from US follow-up.

Ultrasound imaging has some technical limitations, such as the lower contrast of the tissues, that may impair the ability of standard scan to detect fetal lesions. Overlapping the Doppler signal on MRI images provided essential information for the evaluation of lesions such as Galen's venous aneurysm and pulmonary masses. In the near future, RVS might be helpful in diagnosing and managing poorly visualizes fetal conditions, such as pulmonary and cerebral lesions of tuberous sclerosis $[10,11]$. In particular, knowing its association with cardiac rhabdomyomas, a recent study of post-natal tuberous sclerosis which had not been detected either with ultrasound or with RM in prenatal age, has been reported. In the obstetrical field, another interesting application could be represented by the study of the placenta accreta, in which RVS could provide useful information in the management of these high - risk pregnancies.

Endometriosis: The early and accurate definition of the localization of endometriotic lesions is crucial to provide a patient tailored therapy and counseling. In recent years, several studies have tried to solve this issue by analyzing the diagnostic performance of non-invasive methods used for the detection of deep and infiltrating endometriosis such as TVS and MRI [12]. Numerous studies have demonstrated the important role of TVS for the diagnosis of deep infiltrating endometriosis [12,13]. TVS allows a dynamic examination, which is necessary for the diagnosis of the surrounding anatomical structures. However, these kinds of exam often require lifetime training, the diagnostic capacity is often impaired by the operator's experience. MRI provides an excellent visualization of the pelvis and it's characterized by a high resolution of the tissue contrast [13-18].

Therefore, a real-time MRI-TVS combination could provide the benefits of both techniques for the diagnosis of deep infiltrating endometriosis as demonstrated by Millischer et al. The study by Millischer et al. [18] shows that fusion of the two techniques allows a better identification of the localization of deep endometriosis sites and that can potentially improve the ultrasound and MRI single-cell performance. This study was conducted performing RVS on 17 patients who had an MRI in the previous year. 20 patients were enrolled but 3 were excluded for surgery or pregnancy. RVS improves the visibility of anatomical sites where lesions of deep endometriosis are located, and it identifies the adhesions that are characteristic of this pathology. Despite this is a small study, it has managed to underline, for example, that RVS is able to visualize the uterus-sacral ligaments that are normally not visible to the TVS, unless there is fluid, thanks to the overlap of RMI images.

Further studies are needed to confirm the benefits of RVS in the diagnosing and management of patients with endometriosis, assessing whether the potential benefits of this technique will allow a better clinical staging.

Adenomyosis: The term adenomyosis refers to the presence of ectopic glandular endometrial tissue in the context of the myometrium. The pathology may be focal or diffuse with extensive and multiple localizations which can cause symptoms such as menorrhagia, intermenstrual heavy bleeding and chronic pelvic pain. Clinical symptoms are the first indication for the suspect of this pathology. TVS and MRI are both useful to confirm the diagnosis and to define the uterine damage. The clinical feature of this pathology should be evaluated in the first line with TVS, which usually shows an irregular, thickened and heterogeneous myometrium. However, the gold standard imaging technique is MRI [19]. MRI diagnostic criteria of adenomyosis are a focal or diffused magnification, hypointense in sequences $\mathrm{T} 2$ weighed in the region of myometrium invasion. A recent study [20], aimed to evaluate the accuracy of real-time virtual imaging, using ultrasound and MRI. 52 patients with typical signs of adenomyosis such as dysmenorrhea, metrorrhagia and infertility were enrolled.

All patients underwent ultrasound examination followed by the execution of at least three sequences of MRI. A total of 52 patients were evaluated. In 27 cases the diagnosis of adenomyosis was reached with the single use of the TVS. Of these patients, 21 cases showed a widespread adenomyosis and only 6 of them had focal lesions. MRI has diagnosed the pathology in 30 cases. 22 patients were diagnosed for widespread adenomyosis and 8 patients for a focal lesion. In this study, Fusion Imaging has confirmed the diffused adenomyosis in all 22 cases and the focal lesions in the remaining 8. Thanks to the information gained by both techniques, RVS has 
allowed a better identification of the pathology and could improve the accuracy of ultrasound in clinical practice

Cervical cancer: The preoperative diagnostic procedure for patients with cervical cancer includes clinical and gynecological examination and TVS. Abdominal CT is indicated to investigate the presence of extra pelvic disease. MRI is instead the best tool for evaluating the locoregional extension of cervical cancer [21, 22]. The preoperative employment of TVS is poorly used because it is considered to be of limited use. However, recently, more attention has been dedicated to this technique for the detection of parametric infiltration and for predicting treatment response rates in advanced disease with a sensitivity and specificity values of $60 \%$ and $89 \%$, respectively [23]. Through the development of RVS, this value could be improved, allowing a better preoperative staging and therefore the identification of a more effective patient tailored treatment [24]. The study by Theodore et al., examined with RVS 13 patients with cancer of the cervix who performed an MRI. This study showed that Fusion Imaging agrees with the histological diagnosis in $100 \%$ of patients and, while not showing more images than MRI, it increases its information, combining this technique with realtime sonography and making MRI a dynamic exam [24].

In fact, the overlap of ultrasound on MRI allows a better visualization of the parametrical infiltration thanks to the Doppler mode that allows to better define tumor vascularization and neoangiogenesis [24]. By combining MRI and ultrasound is possible to visualize on MRI scan, the specific US sign of parametrical involvement: a disruption in the stromal ring. However, this study is based on a small population with heterogeneous characteristics, so it can be considered a pilot study that needs to be followed by future studies to evaluate the real added value of RVS in cervical cancer diagnoses.

\section{Case Series}

In our case series, five patients were studied for ovarian pathologies and one for endometrial pathology in order to find out the role of Fusion Imaging in these gynecological pathologies which have not yet been investigated in the present literature Table 3 .

Table 3: Case series of patients enrolled from Gynecology Department of Sant 'Andrea Hospital and evaluated with Fusion Imaging.

\begin{tabular}{|c|c|c|c|c|c|}
\hline Case & Age & Pathology & US Findings & MRI/CT & Surgery and Histological Findings \\
\hline 1 & 59 & $\begin{array}{l}\text { Ovarian serous } \\
\text { epithelial carcinoma } \\
\text { residual disease }\end{array}$ & $\begin{array}{l}\text { left ovary solid } \\
\text { formation - color } \\
\text { score 3; right ovary } \\
\text { solid-liquid pattern } \\
\text { formation color score } \\
\quad 3\end{array}$ & $\begin{array}{l}\text { CT-ovaries solid lesions with } \\
\text { signs of diffuse hypodensity } \\
\text { as well as presence of } \\
\text { high cellular and marked } \\
\text { tissue and heterogeneous } \\
\text { enhancement after contrast }\end{array}$ & $\begin{array}{c}\text { Increased size left ovary of } 5 \mathrm{~cm} \text { and increased } \\
\text { size right ovary of } 5,5 \mathrm{~cm} \text { replaced with solid new } \\
\text { growth. Histological examination confirmed the } \\
\text { diagnosis of serous epithelial carcinoma bilateral } \\
\text { high-grade ovary, p53 +., replaced with solid new } \\
\text { growth. }\end{array}$ \\
\hline 2 & 64 & $\begin{array}{l}\text { Ovarian mucinous } \\
\text { cystadenoma }\end{array}$ & $\begin{array}{l}\text { Right ovary } \\
\text { multilocular cyst with } \\
\text { dense fluid content }\end{array}$ & $\begin{array}{l}\text { CT-massive hypodense } \\
\text { formation, with a fluid-like } \\
\text { content }\end{array}$ & $\begin{array}{l}\text { Histological examination highlighted the cystic } \\
\text { formation of the maximum diameter of } 18 \mathrm{~cm} \\
\text { in continuity with the tuba and with the fimbria } \\
\text { of the length of } \mathrm{cm} 11 \text {. At the opening the cyst it } \\
\text { appeared to be multiplied and replete with clear } \\
\text { fluid. Definitive diagnosis was ovarian mucinous } \\
\text { cystadenoma. }\end{array}$ \\
\hline 3 & 20 & $\begin{array}{l}\text { Ovarian cystic } \\
\text { teratoma }\end{array}$ & $\begin{array}{l}\text { Right ovary unilocular } \\
\text { cyst with mixed echoes } \\
\text { and shadows }\end{array}$ & $\begin{array}{l}\text { MRI- Cyst of right ovarian } \\
\text { with high intensity in T1 and } \\
\text { hypo intensive wall in T2 }\end{array}$ & $\begin{array}{c}\text { Macroscopic description referred cystic } \\
\text { formation partially open of } 5,5 \times 4 \mathrm{~cm} \text { size with } \\
\text { grayish and semiliquid content. The other surface } \\
\text { appeared bright and shiny. The internal one } \\
\text { presented a } 3,5 \mathrm{~cm} \text { nidus from which numerous } \\
\text { piled emerged. Definitive diagnosis was mature } \\
\text { teratoma. }\end{array}$ \\
\hline 4 & 33 & $\begin{array}{c}\text { Ovarian } \\
\text { endometrioma }\end{array}$ & $\begin{array}{l}\text { left ovarian unilocular } \\
\text { cyst, with corpuscular } \\
\text { and hemorrhagic } \\
\text { content and ground } \\
\text { glass echogenicity }\end{array}$ & $\begin{array}{l}\text { MRI- hyperintense } \\
\text { in } \mathrm{T} 1 \text { sequences and } \\
\text { inhomogeneous hyperintense } \\
\text { in } \mathrm{T} 2 \text {, with fluid level in the } \\
\text { context, with blood content in } \\
\text { various phases of hemoglobin } \\
\text { degradation. }\end{array}$ & $\begin{array}{l}\text { Histological examination confirmed the } \\
\text { diagnosis of ovarian endometriosis of the cystic } \\
\text { formation arrived in fragments of } 5 \mathrm{~cm} \text { diameter } \\
\text { in aggregate, with smooth and opaque external } \\
\text { surface and fibrin-hemorrhagic content. }\end{array}$ \\
\hline 5 & 54 & $\begin{array}{l}\text { Ovarian serous } \\
\text { cystadenoma }\end{array}$ & $\begin{array}{l}\text { Left ovary anechoic } \\
\text { unilocular cyst with } \\
\text { papillary structures in } \\
\text { the wall }\end{array}$ & $\begin{array}{l}\text { MRI- high intensity in } \mathrm{T} 1 \text { and } \\
\text { low intensity in T2, it was } \\
\text { characterized by thin walls } \\
\text { and fluid content without the } \\
\text { solid component }\end{array}$ & $\begin{array}{l}\text { Histological findings documented } 6 \mathrm{~cm} \text { diameter } \\
\text { cyst with smooth outer wall and serous yellow } \\
\text { citrine fluive content, at cut. At the opening } \\
\text { it appeared single chambered with papillary } \\
\text { formations. The diagnosis was atypical } \\
\text { proliferating serous cystadenoma (borderline). }\end{array}$ \\
\hline 6 & 53 & $\begin{array}{c}\text { uterine } \\
\text { endometrioid } \\
\text { adenocarcinoma }\end{array}$ & $\begin{array}{l}\text { hyperechogen } \\
\text { formation, color score } \\
\text { 3, on the posterior } \\
\text { uterine wall }\end{array}$ & $\begin{array}{l}\text { CT- most vascularized } \\
\text { myometrial stroma, with a } \\
\text { greater enhancement than the } \\
\text { neoplasia }\end{array}$ & $\begin{array}{l}\text { At macroscopic examination uterus was } 12 \times \\
9 \times 6 \mathrm{~cm} \text { size and the endometrium appeared } \\
\text { occupied by a neoformation that seemed } \\
\text { to involve the upper third of the cervix and } \\
\text { the myometrium, at the cut. Histological } \\
\text { diagnosis documented uterine endometrioid } \\
\text { adenocarcinoma. }\end{array}$ \\
\hline
\end{tabular}


Patient 1: 59 years old, affected by residual ovarian bilateral serous epithelial carcinoma after 3 cycles of neoadjuvant chemotherapy with Carboplatin AUC5 and Paclitaxel 175mg / mq every 21 days. CT showed bilaterally increased volume of the ovaries, with two solid lesions: maximum dimensions of $57 \times 40 \mathrm{~mm}$ on the right side and $48 \times 37 \mathrm{~mm}$ on the left, with signs of diffuse hypodensity as well as presence of high cellular and marked tissue and heterogeneous enhancement after contrast. Transvaginal sonography (TVS) showed the presence of peritoneal spread and highlighted the increased size of left ovary (of 50x34mm), with a solid formation vascularized to the Color Doppler (color score 3). The right ovary showed a solid-liquid formation pattern of 59x38mm (color score 3). Both lesions were suspicious for residual disease. Fusion enabled the overlap of images from CT and ultrasound. This virtual navigation allowed to connect information from different survey systems and to evaluate the extension of the disease more accurately. The images obtained with RVS showed an enlargement of left ovary of $49.4 \times 36.7 \mathrm{SSmm}$ and right ovary of $54.8 \times 45 \mathrm{Smm}$. The patient underwent to interval surgery and the comparison of the images obtained with Fusion with the final histological exam proved the method to be accurate (Figures $1 \& 2$ ).

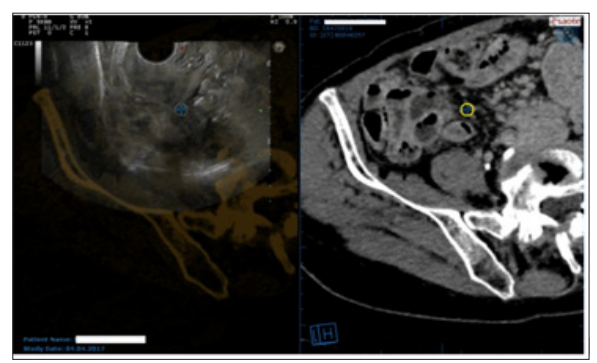

Figure 2: Patient 1, right ovary US/CT overlap images.

Patient 2: 64 years old, with diagnosis of mucinous cystadenoma of the right ovary. At the pelvic sonography emerged the presence of a voluminous multilocular cyst $(22 \mathrm{x} 18 \mathrm{~cm})$ with dense fluid content. The left ovary could not be found due to the space occupied by the mass. CT confirmed the presence of a massive hypodense formation, with a fluid-like content. The cyst measured $20 \times 23 \times 19 \mathrm{~cm}$. RVS showed the reports of ovarian cyst against the surrounding pelvic organs and give more indications for the surgical treatment. From the overlap of the ultrasound images with tomographic images, the dimension of the cyst was $19.5 \times 16.5 \mathrm{~cm}$, occupying almost the whole pelvic floor, extending to the right flank and dislocating the small bowel and colon. The patient underwent to laparotomic cystectomy after aspiration of the mucinous content (Figure 3).

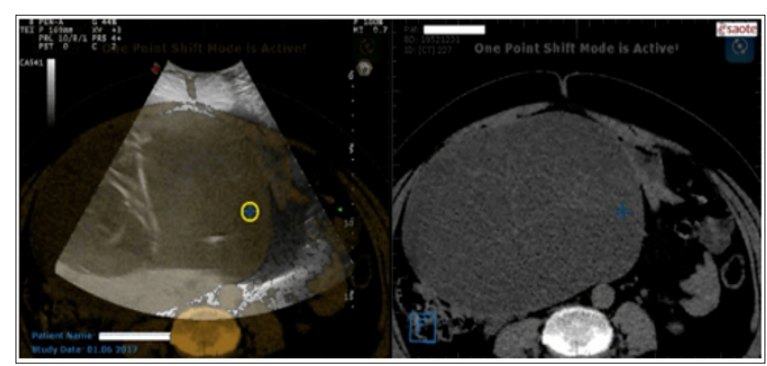

Figure 3: Patient 2, US/CT overlap images.
Patients 3: 20 years old, came to our observation after MRI control for disc herniation pathology, which highlighted a circular pattern of the right ovary with high intensity in T1 and hypo intensive wall in $\mathrm{T} 2$ of $11 \mathrm{x} 8 \mathrm{~cm}$. Ultrasound allowed us to investigate a wide formation with the eco structural markers of the dermoid cystic teratoma $(80 \times 53 \mathrm{~mm})$, with a residual gonadal parenchyma of $21 \times 9 \mathrm{~mm}$. Our RVS investigation confirmed the diagnosis of a cystic formation with transonic content with a thin linear hyperechogenic echoes placed within the cyst of $\mathrm{mm}$. The patient underwent to laparoscopic cystectomy surgery. Histological result confirmed the presence of a dermoid cyst (Figure 4).

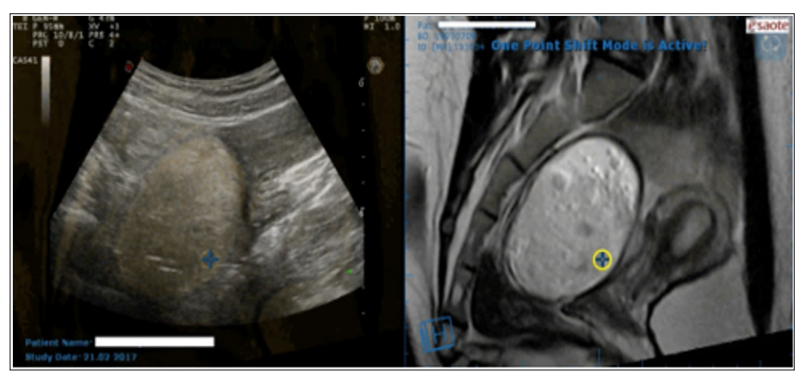

Figure 4: Patient 3, MRI/US overlap images.

Patient 4: 33 years old, with deep infiltrating endometriosis diagnosis. Ultrasound documented left ovarian endometrioma, 79x70mm, with corpuscular and hemorrhagic content. An adherent syndrome was noted, probably of endometriotic nature, with kissing ovaries and involvement of the bowel in a single adherent complex dislocated laterally in recto-uterine pouch. MRI showed the presence of a circular formation in the left ovary, hyperintense in T1 sequences and inhomogeneous hyperintense in T2, with fluid level in the context, about $7 \times 5 \mathrm{~cm}$, with blood content in various phases of hemoglobin degradation referable to endometriotic cysts. Our RVS examination confirmed the widespread endometriosis in the pelvic cavity, mostly visible in the anterior left region. The cyst dimensions were $7 \times 5 \mathrm{~cm}$. The patient underwent to laparoscopic adhesiolysis and cystectomy surgery (Figure 5).

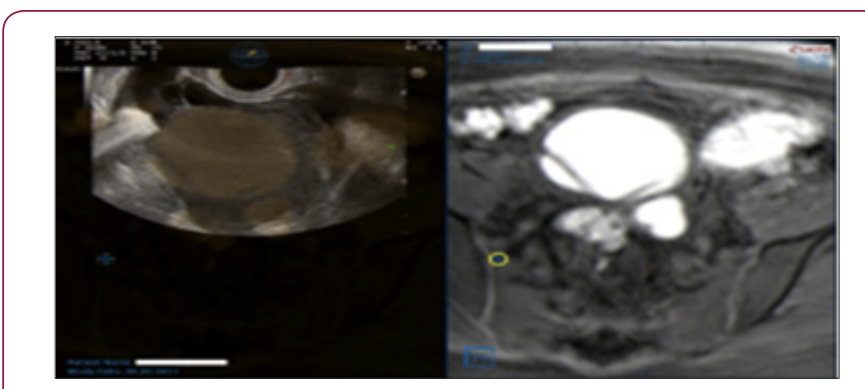

Figure 5: Patient 4, MRI/US overlap images.

Patient 5: 54 years old, ultrasound exam showed anechoic cyst of $5 \times 4 \mathrm{~cm}$ of the left ovary, with papillary structures within the cystic wall. MRI showed a mass of 50x45 $\mathrm{mm}$ and unilocular appearance, with high intensity in T1 and low intensity in T2, characterized by thin walls and fluid content without the solid component. With RVS examination the cyst was estimated to be of $4.9 \times 4 \mathrm{~mm}$ big. The histologic results after laparoscopic cystectomy surgery confirmed the suspected diagnosis of serous cystoadenoma (Figure 6). 


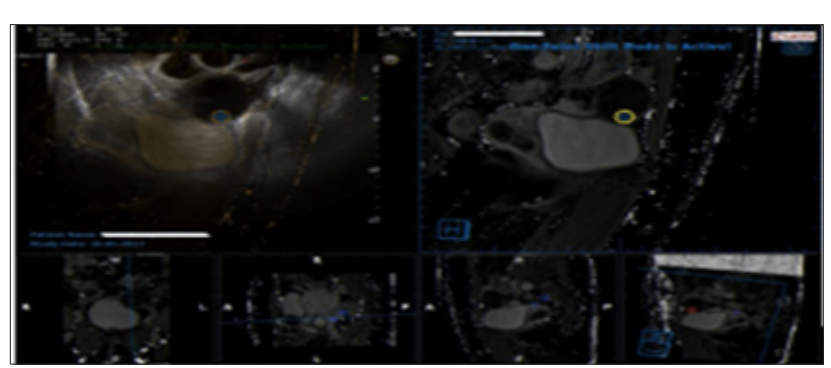

Figure 6: Patient 5, MRI/US overlap images.

Patient 6: 53 years old, with abnormal uterine bleeding. Transabdominal and transrectal sonography highlighted enlarged uterus (mm100x55x80) with a hyperechogenic formation of $\mathrm{mm}$ $40 \times 60$, color score 3 , on the posterior uterine wall of uncertain interpretation (differential diagnosis of polyp, intracavitary myoma or dysplasia). Biopsy hysteroscopy reported a uterine endometrioid adenocarcinoma diagnosis. Staging CT/PET showed high intensity fixation of the radioisotope at the uterine cavity at the level of the uterine body. A pathologic fixation was observed in the caudal region, probably in proximity of the uterine neck. There was no evidence of lymph node involvement. At the CT scan the myometrial stroma, showed a greater enhancement than the neoplasia. RVS showed an enlarged uterus (59x87mm). The histologic exam after hysteroannessiectomy confirmed the diagnosis of a uterine endometrioid adenocarcinoma of $12 \times 6 \times 9 \mathrm{~cm}$ (Figure 7).

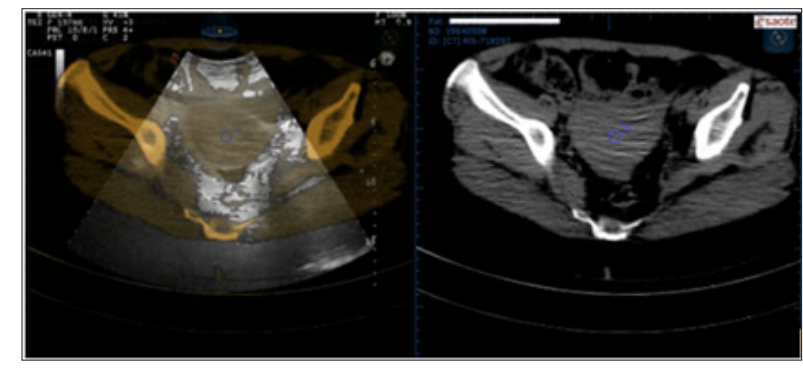

Figure 7: Patient 6, US/CT overlap images.

\section{Discussion}

The role of fusion imaging technology in Gynecology and Obstetrics field has not yet been defined. Other medical applications were more experienced in urology [25-32], hepatology [33, 34] and breast pathology [35-40]. CE-MRI has become an essential technique in this field breast cancer, a disease with an incidence of 37,000 new cases/year in Italy [35], that affects 1 woman on 10 and represents $25 \%$ of all tumors in females [36-40].

The MRI guided biopsy is extensively used to study lesions that are not visible from ultrasound or mammography [41], providing high-resolution images. However, this technique it's still not widely available and it doesn't allow a real-time sampling. Fusion of MR-US seems to be a suitable instrument for biopsy suspected breast lesions. The combination of MRI and ultrasound not only improve images resolution, but also shorten the exam timing [42]. In addition, it makes possible the real-time visualization of lesions, allowing the navigation of the volumes provided by the MRI under the ultrasound guide. Several studies showed excellent results highlighting its precision and reproducibility $[8,10,15]$.

Fusion Imaging technique can better define also the lymph node status by documenting the presence of metastasis prior to surgery bypassing the need of sentinel lymph node biopsy [43, 44]. Yamamoto et al reported an accuracy in metastasis detection of $81 \%$ [45]. As we have reported in our review fields of application of Fusion Imaging in gynecology and obstetrics are still to be defined. In obstetric pathologies, it seems to be a feasible tool that allows to better define fetal anomalies avoiding continuous imaging examinations. In fact, as shown in recent studies [8,9], RVS could improve evaluation of CNS anomalies. However, these pilot studies need to be confirmed with studies on a larger and more homogeneous population. For pregnant patients, other conditions that can benefit from the fusion technique are invasive procedures driven by imaging. Fusion imaging could allow the execution of sonography-driven procedures with overlapping information provided by MRI. Finally, RVS could also be useful for educational purposes, enabling easier recognition of anatomical structures. This may be relevant for better recognition of brain structures such as optic nerves and chiasma, olfactory bulbs, or semicircular canal. Appropriate visualization of these structures only through ultrasound is difficult and a proper recognition of presence or absence of these structures can play a crucial role in prenatal counseling.

In conclusion, although the advantages described with the use of this technique, careful evaluation of inappropriate overlapped images of the two modes needs to be further studied. Despite the multidimensional fusion images will allow an easier and safer prenatal diagnosis, other prospective studies are needed to increase the information on the use of this new technique. The advantages observed in the obstetrics studies, such as the use of Doppler mode and the ease of reproducibility of the examination, can also be exploited in investigations on benign and malignant gynecological diseases. In particular, some small studies have been done on endometriosis and adenomyosis giving importance to the concept that these women must undergo a close follow-up to define the evolution of the disease. If the usefulness of fusion was indeed confirmed also for follow-up, it would be avoided to subject these women to continuous and repeated exams as magnetic resonances. The Doppler function, on the other hand, has been shown to play an important role in better defining the information coming from the MRI on cervical cancer, in particular, for what concerns neoangiogenesis and parametrium infiltration [24].

However, future studies are needed on these and other diseases to define whether fusion can play a role as a diagnostic, prognostic and therapeutic tool in gynecology. Different interesting gynecological pathologies, such as benign and malignant alteration of the ovary and endometrium have not yet been thoroughly evaluated by RVS, so we reported a case series which investigates these pathologies. The primary workup of a patient with a suspicious pelvic mass usually includes an ultrasound and/or 
abdominal/pelvic MRI scan. Both techniques have high sensitivity and specificity rate, especially when performed in reference centers with sophisticated equipment and skilled operators [4648]. Preoperative characterization of ovarian cancer often allows a tailored treatment in terms of surgery or neo-adjuvant therapy. Fusion Imaging could be useful in the difficult differentiation between benign, borderline and malignant formations (Figures 1-4). The use of sonography provides important information in the assessment of patients with abnormal uterine bleeding (Figure 7), one of the first sign of endometrial cancer [49]. The main aspects evaluated with sonography are the thickness of the endometrium, the endo-myometrial junction, referable to the infiltration of neoplasia in the myometrium, and the presence of a fluid collection in the uterine cavity [50].

In addition, power Doppler can be useful in evaluating the vascular structure of the neoplasia [51]. The diagnostic accuracy of TVS in the assessment of involvement cervical is similar to the one obtained from the MRI (92\% versus 85\%) [52]. Currently, MRI proves to be superior to TVS both in the evaluation of cervical extension and myometrial infiltration [53]. A meta-analysis has shown how MRI is significantly better than the US in the evaluation of the depth of myometrial invasion. MRI evaluates the extension to the uterine cervix with an accuracy ranging from $86 \%$ to $95 \%$ [54]. The overlap of information from the two techniques could permit an optimal management of the disease. From our review emerges that a key factor in achieving diagnostic accuracy is that RVS has to be performed right after the MRI or CT investigations. This is due to the fact that, several pathological processes, such as neoplasia, can undergo significant dimensional changes during a small amount of time. To achieve a correct overlap of images through RVS, the dimension parameter is indispensable. Physiological and anatomical mutations, besides temporal changes, can increase the risk of images incompatibility. For example, one only has to consider how much the weight modifies during pregnancy, and how a full or empty bladder or the bowel conditions are able to modify the anatomy of pelvic organs.

Another necessary step for the proper execution of the exam is the choice of a proper target. Usually the target selected to study abdominal anatomy is the umbilical site. However, usually, this choice is linked to the use of convex probes for trans-abdominal applications. For gynecological investigations, the transvaginal approach should be preferred. It would be appropriate to use a static structure like the rectum, as an eligible target of such a dynamic compartment. The peritoneum, the pelvic band, the elevator anus muscle and fibrous thickening that are formed around rectal vessels fix the rectum. These reports provide stability to the segment that is less inclined to conformational changes. So, ultrasound examination allows us to investigate all spaces and plans dynamically but at the same time does not possess the resolution and contrast power characteristic of MRI and CT, while RVS has the main advantage of combining the benefits of all the methods currently in use. Further studies conducted on a larger, wider and homogeneous population are needed to reinforce the results achieved in order to obtain a better definition of the field of application and the diagnostic improvement of this new fascinating technique.

\section{References}

1. (2003) American College of Radiology ACR practice guideline for the performance of ante partum obstetrical ultrasound. ACR practice guidelines and technical standards pp. 625-631.

2. Bricker L, Neilson JP (2007) Routine Doppler ultra sound in pregnancy. Cochrane Database Syst Rev 2: CD001450.

3. Tortoni MR, Vedmedovska N, Betran AP, Allen T, Merialdi M, et al. (2009) Safety of ultrasonography in pregnancy: WHO systematic review of the literature and meta- analysis. Ultrasound Obstet Gynecol 33(5): 599608.

4. Garel C (2008) Imaging the fetus: when does MRI really help? Pediatr Radiol 38: 467-470.

5. Prayer D, Brugger PC (2007) Investigation of normal organ development with fetal MRI. Eur Radiol 17(10): 2458-2471.

6. Pugash D, Brugger PC, Bettelheim D, Prayer D (2006) Prenatal ultrasound and fetal MRI: the comparative value of each modality in prenatal diagnosis. Eur J Radiol 68(2): 214-226.

7. Millischer A, Sonigo P, Ville Y, Brunelle F, Boddaert N, et al. (2013) Standardized anatomical examination of the fetus at MRI. A feasibility study. Ultrasound Obstet Gynecol 42(5): 553-559.

8. Salomon LJ, Bernard JP, Millischer AE, Sonigo P, Brunelle F, et al. (2013) MRI and ultrasound fusion imaging for prenatal diagnosis. Am J Obstet Gynecol 209(2): 148 e1-e9.

9. Bernardo S, Gianicotti A, Antonelli A, Rizzo G, Vinci V, et al. (2017) MRI and US in the evaluation of fetal anomalies: the need to work together. Prenat Diagn 37(13): 1343-1349.

10. Alamo L, Gudinchet F, Reinberg O, Vial Y, Francini K, et al. (2012) Prenatal diagnosis of congenital lung malformations. Pediatr Radiol 42(3): 273283.

11. Saada J, Hadj Rabia S, Fermont L, Le Bidois J, Bernardes LS, et al. (2009) Prenatal diagnosis of cardiac rhabdomyomas: incidence of associated cerebral lesions of tuberous sclerosis complex. Ultrasound Obstet Gynecol 34(2): 155-159.

12. Koninckx PR, Me uleman C, Demeyere S, Lesaffre E, Cornillie FJ (1991) Suggestive evidence that pelvic endometriosis is a progressive disease, whereas deeply infiltrating endometriosis is associated with pelvic pain. Fertility and sterility 55(4): 759-765.

13. Giudice LC (2010) Clinical practice Endometriosis. N Eng J Med 362(25): 2389-2398.

14. Kinkel K, Chapron C, Balleyguier C, Fritel X, Dubuisson JB, et al. (1999) Magnetic resonance imaging characteristics of deep endometriosis. Hum Reprod 14(4): 1080-1086.

15. Piketty M, Chopin N, Dousset B, Millischer Bellaische AE, Roseau G, et al. (2009) Preoperative work-up for patients with deeply infiltrating endometriosis: transvaginal ultrasonography must definitely be the first-line imaging examination. Hum Reprod 24(3): 602-607.

16. Abrao MS, Goncalves MO, Podgaec S, Chamie LP, Blasbalg R (2007) Comparison between clinical examination, transvaginal sonography and magnetic resonance imaging for the diagnosis of deep endometriosis. Hum Reprod 22(12): 3092-3097.

17. Bazot M, Darai E, Hourani R, Thomassin I, Cortez A, et al. (2004) Deep pelvic endometriosis: MR imaging for diagnosis and prediction of extension of disease. Radiology 232(2): 379-389.

18. Millischer AE, Salomon LJ, Santulli P, Borghese B, Dousset B, et al. (2015) Fusion imaging for evaluation of deep infiltrating endometriosis: feasibility and preliminary results. Ultrasound Obstet Gynecol 46: 109117.

19. Bazot M, Fiori O, Darai E (2006) Adenomyosis in endometriosis prevalence and impact on fertility. Evidence from magnetic resonance imaging. Hum Reprod 21(4): 1101-1102. 
20. Vinci V, Saldari M, Sergi ME, Bernardo S, Rizzo G, et al. (2017) MRI, US or real-time virtual sonography in the evaluation of adenomyosis? Radiol med 122(5): 361-368.

21. Jemal A, Bray F, Center MM, Ferlay J, Ward E, Forman D (2011) Global cancer statistics. CA Cancer J Clin 61(2): 69-90.

22. Subak LL, Hricak H, Powell CB, Azizi L, Stern JL (1995) Cervical carcinoma: computed tomography and magnetic resonance imaging for preoperative staging. Obstet Gynecol 86(1): 43-50.

23. Testa AC, Ludovisi M, Manfredi R, Zannoni G, Gui B, et al. (2009) Transvaginal ultrasonography and magnetic resonance imaging for assessment of presence, size and extent of invasive cervical cancer. Ultrasound Obstet Gynecol 34(3): 335-344.

24. Theodore C, Levaillant JM, Capmas P, Chabi N, Skalli D, et al. (2017) MRI and Ultrasound Fusion Imaging for Cervical Cancer. Anticancer Res 37(9): 5079-5085.

25. Heidenreich A, Aus G, Bolla M, Matveev V, Zattoni F (2008) EAU Guidelines on Prostate Cancer. Eur Urol 53(1): 68-80.

26. Moussa AS, Meshref A, Schoenfield L, Masoud A, Abdel-Rahman S, et al. (2010) Importance of additional "extreme" anterior apical needle biopsies in the initial detection of prostate cancer. Curr Urol 75(5): 1034-1039.

27. Meng MV, Franks JH, Presti JC Jr, Shinohara K (2003) The utility of apical anterior horn biopsies in prostate cancer detection. Urol Oncol 21(5): 361-365.

28. Murphy IG, Ni Mhurchu E, Gibney RG, Mc Mahon CJ (2017) MRI directed cognitive fusion-guided biopsy of the anterior prostate tumors. Diagn Interv Radiol 23 (2): 87-93.

29. Cool DW, Zhang X, Romagnoli C, Izawa JI, Romano WM, et al. (2015) Evaluation of MRI-TRUS fusion versus cognitive registration accuracy for MRI targeted, TRUS guided prostate biopsy. AJR Am J Roentgenol 204: 83-91.

30. Baur ADJ, Collettini F, Enders J, Maxeiner A, Schreiter V, et al. (2017) MRITRUS for electrode positioning during irreversible electroporation for treatment of prostate cancer. Diagn Interv Radiol 23(4): 321-325.

31. Deipolyi AR, Golberg A, Yarmush ML, Arellano RS, Oklu R (2014) Irreversible electroporation: evolution of a laboratory technique in interventional oncology. Diagn Interv Radiol 20(2): 147-154.

32. Dickinson L, Hu Y, Ahmed HU, Clare Allen, Alex P Kirkham, et al. (2013) Image directed tissue-preserving focal therapy of prostate cancer: a feasibility study of a novel deformable magnetic resonance-ultrasound (MR-US) registration system. BJU international 112(5): 594-601.

33. Lee MW (2014) Fusion imaging of real-time ultrasonography with CT or MRI for hepatic intervention. Ultrasonography 33(4): 227-239.

34. Mauri G, Cova L, De Beni S, Ierace T, Tondolo T, et al. (2015) Real-Time USCT/MRI Image Fusion for Guidance of Thermal Ablation of Liver Tumors Undetectable with US: Results in 295 Cases. Cardiovasc Intervent Radiol 38(1): 143-151.

35. Mann RM, Kuhl CK, Kinkel K, C Boetes (2008) Breast MRI: guidelines from the European Society of Breast Imaging. Eur Radiol 18(7): 130718.

36. Nakano S, Yoshida M, Fujii K, Yorozuya K, Mouri Y, et al. (2009) Fusion of MRI and sonography image for breast cancer evaluation using real time virtual sonography with magnetic navigation: first experience. Jpn J Clin Oncol 39(9): 552-559.

37. Nakano S, Kousaka J, Fujii K, Yorozuya K, Yoshida M, et al. (2012) Impact of real time virtual sonography, a coordinated sonography and MRI system that uses an image fusion technique, on the sonographic evaluation of MRI detected lesions of the breast in second look sonography. Breast Cancer Res Treat 134(3): 1179-1188.

38. Sardanelli F, Podo F, D Agnolo G, Verdecchia A, Santaquilani M, et al. (2007) Multicenter comparative multimodality surveillance of women at genetic-familial high risk for breast cancer (HIBCRIT study): interim results. Radiology 242(3): 698-715

39. Lee SG, Orel SG, Woo IJ, Eva Cruz Jove, Mary E Putt, et al. (2003) MR imaging screening of the contralateral breast in patients with newly diagnosed breast cancer: preliminary results. Radiology 226(3): 773778 .

40. Liberman L, Morris EA, Dershaw DD, Andrea F Abramson, Lee K Tan (2003) MR imaging of the ipsilateral breast in women with percutaneously proven breast cancer. Am J Roentgenol 180(4): 901-910.

41. Teifke A, Lehr HA, Vomweg TW, Alexander Hlawatsch, Manfred Thelen (2003) Outcome analysis and rational management of enhancing lesions incidentally detected on contrast enhanced MRI of the breast. Am J Roentgenol 181(3): 655-662.

42. Fausto A, Rizzatto G, Preziosa A, Gaburro L, Washburn MJ, et al. (2012) A new method to combine contrast enhanced magnetic resonance imaging during live ultrasound of the breast using volume navigation technique: a study for evaluating feasibility, accuracy and reproducibility in healthy volunteers. Eur J Radiol 81(3): 332-337.

43. Rahbar H, Partridge SC, Javid SH, Lehman CD (2012) Imaging axillary lymphnodes in patients with newly diagnosed breast cancer. Curr Probl Diagn Radiol 41(5): 149-158.

44. Pons EP, Azcon FM, Casas MC, Meca SM, Espona JLG (2014) Real time MRI navigated US: role in diagnosis and guided biopsy of incidental breast lesions and axillary lymph nodes detected on breast MRI but not on second look US. Eur J Radiol 83(6): 942-950.

45. Yamamoto S, Maeda N, Tamesa M, Nagashima Y, Yoshimura K (2012) Prospective ultrasonographic prediction of sentinel lymph node metastasis by real-time virtual sonography constructed with three dimensional computed tomography-lymphography in breast cancer patients. Breast Cancer 19(1): 77-82.

46. Forstner R, Meissnitzer M, Cunha TM (2016) Update on Imaging of Ovarian Cancer. Current Radiology Reports 4: 31.

47. Timmermann D, Schwarzler P, Collins WP, Claerhout F, Coenen M, et al. (1999) Subjective assessment of adnexal masses with the use of ultrasonography: an analysis of interobserver variability and experience. Ultrasoud Obstet Gynecol 13(1): 11-16.

48. Komatsu T, Konishi I, Mandai M, (1996) e Coll: Adnexal masses: transvaginal US and gadolinium enhanced MR imaging assessment of intratumoral structure, Radiology 198: 109-115.

49. Cook SL, Weiss NS (2006) Endometrial Cancer, Cancer Epidemiology and Prevention. In Schottenfeld D and Fraumeni JF Jr (Eds.). ( $3^{\text {rd }}$ Edition) Oxford University Press, New York, USA pp. 1027-1034.

50. Ferrazzi E, Torri V, Trio D, Zannoni E, Filiberto S, et al. (1996) Sonographic endometrial thickness: a useful test to predict atrophy in patients with postmenopausal bleeding. An Italian multicenter study. Ultrasound Obstet Gynecol 7(5): 315-321.

51. Epstein E, Valentin L (2006) Grey-scale ultrasound morphology in the presence or absence of intrauterine fluid and vascularity ossesse by color Doppler for discrimination between benign and malignant endometrium in women with postmenopausal bleeding. Ultrasound Obstet Gynecol 28(1): 89-95.

52. Alcazar JL, Galvan R, Albela S, Martinez S, Pahisa J, et al. (2009) Assessing Myometrial infiltration by endometrial cancer: uterine virtual navigation with three dimensional US. Radiology 250(3): 776-783.

53. Savelli L, Ceccarini M, Ludovisi M, Fruscella E, De Iaco PA, et al. (2008) Preoperative local staging of endometrial cancer: transvaginal sonography vs. magnetic resonance imaging. Ultrasound Obstet Gynecol 31(5): 560-566.

54. http://www.reteoncologica.it/images/stories/area_operatori/ raccomandazioni_di_rete/ginecologico/T_endometriale_2014.pdf 
ISSN: 2574-1241

DOI: $10.26717 / B J S T R .2018 .10 .001882$

Donatella Caserta. Biomed J Sci \& Tech Res

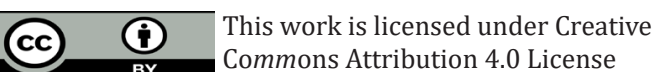

Submission Link: https://biomedres.us/submit-manuscript.php

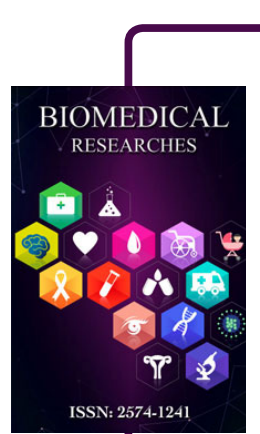

Assets of Publishing with us

- Global archiving of articles

- Immediate, unrestricted online access

- Rigorous Peer Review Process

- Authors Retain Copyrights

- Unique DOI for all articles

https://biomedres.us/ 